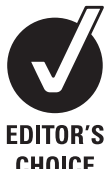

CHOICE

\title{
The effect of cigarette smoking on asthma control during exacerbations in pregnant women
}

\author{
Vanessa E Murphy, ${ }^{1}$ Vicki L Clifton, ${ }^{2}$ Peter G Gibson ${ }^{3}$
}

- Supplementary material is published online. To view these files please visit the journal online (http://thorax.bmj.com).

${ }^{1}$ Centre for Asthma and Respiratory Diseases, University of Newcastle and Hunter Medical Research Institute, Australia

${ }^{2}$ Department of Paediatrics and Reproductive Health, University of Adelaide, Australia

${ }^{3}$ John Hunter Hospital, Australia

\section{Correspondence to}

Dr Peter G Gibson, Department of Respiratory and Sleep Medicine, Level 3, John Hunter Hospital, Locked Bag 1, HRMC, Newcastle NSW 2310, Australia; peter.gibson@ hnehealth.nsw.gov.au

Received 5 August 2009 Accepted 18 April 2010
ABSTRACT

Background Smoking and severe asthma exacerbations in pregnancy are risk factors for low birth weight babies. No studies have assessed the clinical implications of smoking on asthma exacerbations in pregnancy.

Methods Pregnant women with current asthma $(n=80)$ were prospectively assessed at clinic visits $(18,30$, 36 weeks), during exacerbations and with fortnightly phone calls. The asthma control questionnaire was administered at each contact and exacerbations classified as severe (requiring medical intervention) or mild (self-managed). Medications, self-management skills, smoking history, fractional exhaled nitric oxide (FENO), exhaled carbon monoxide (ECO) and lung function were assessed. Pregnant women without asthma (controls, $n=46$ ) were assessed prospectively at clinic visits.

Results Women with asthma were more likely to smoke (34\% current smokers) than women without asthma (15\% current smokers). In women with asthma, the median (IOR) exacerbation rate during pregnancy was $2.0(1.0-3.0)$ in current smokers, $2.0(1.0-3.0)$ in ex-smokers and $1.5(1.0-2.0)$ in never smokers. The asthma control score during exacerbations was higher in current smokers (median (IOR) 2.17 (1.17-2.7)) compared with never smokers (1.17 (0.8-2.17), $p=0.056)$. An adjusted linear regression model found that smoking was significantly associated with higher asthma control score during exacerbation $(p=0.04)$. Birth weights were lower among children of smokers than non-smokers ( $p=0.023$ control group, $p=0.086$ asthma group).

Conclusions During pregnancy, asthma exacerbations are more common and more severe in current smokers than never smokers. The risk of effects of maternal asthma on the fetus may be greater among smokers.

\section{INTRODUCTION}

Smoking during pregnancy is a significant risk factor for poor perinatal outcomes, including low birth weight, premature birth and infant mortality. ${ }^{1}$ Despite this, many pregnant women continue to smoke during pregnancy. In Australia, the rate of smoking among pregnant women is $\sim 20 \%$, and the quit rate in pregnancy is surprisingly low, with heavy smokers less likely to quit. ${ }^{2}$ Studies from around the world have suggested that pregnant women with asthma are more likely to smoke than pregnant women without asthma, ${ }^{3-14}$ with few exceptions. ${ }^{15-17}$ Women with asthma are also at an increased risk of low birth weight, ${ }^{18}$ and severe asthma exacerbations during pregnancy are associated with a 2.5-fold increased risk of low birth weight. ${ }^{19}$ Thus, women with asthma who smoke during pregnancy may be at increased risk of low birth weight from the combined effects of smoking, asthma and severe asthma exacerbations.
There is also the potential for smoking to worsen asthma control during pregnancy, and further increase risks to the fetus. Smoking is associated with persistent changes in asthma, including a greater decline of lung function with age, ${ }^{20}$ poorer symptom control $^{21}$ and reduced response to corticosteroids. ${ }^{22}$ It was previously found that asthma control among non-pregnant adult smokers was worse than in non-smokers ${ }^{21}$ and that smokers had significantly higher scores for each individual item than never smokers, with the exception of lung function. ${ }^{21}$ There are limited studies investigating the frequency or severity of exacerbations among smokers with asthma compared with non-smokers with asthma, with some evidence that current smokers report more frequent symptoms, ${ }^{23}$ and may have a higher risk for hospitalisation for acute asthma. ${ }^{24}$

Asthma control and exacerbations have not previously been assessed in smokers during pregnancy. We hypothesised that pregnant women with asthma who were current smokers would experience more frequent exacerbations than never smokers, and that these exacerbations would be more severe, indicated by a higher asthma control questionnaire (ACQ) score.

\section{METHODS}

Pregnant women (18-43 years) were consecutively recruited through the John Hunter Hospital antenatal clinics and the community between July 2004 and December 2006. Women signed written informed consent for participation. Approval was provided by the University of Newcastle and Hunter New England Health Human Research Ethics Committees. A research midwife located in the antenatal clinic explained the study to potentially eligible participants, and referred those potentially interested to research staff who obtained written informed consent. This approach allowed prospective recruitment of consecutive new referrals to the antenatal clinic.

Pregnant women with physician-diagnosed asthma $(n=85)$ were prospectively followed from recruitment (mean 14.8, SD (3.0) weeks gestational age) with clinic visits at $\sim 18,30$ and 36 weeks gestation (visit 1, 2 and 3), and fortnightly phone calls between visits. Women were assessed during exacerbation where possible. Four women with asthma did not have current symptoms or medication use during the pregnancy and were considered in remission. One woman completed one visit and insufficient data about smoking status were available. Results from these five women were excluded from the present analysis.

The ACQ $6^{25}$ was administered at each contact. The ACQ is a validated tool assessing the severity 
of night waking, morning asthma symptoms, activity limitation, shortness of breath, wheeze, short acting $\beta_{2}$-agonist use and lung function. ${ }^{25} 26$ This shortened version did not include the lung function item, allowing us to administer the questionnaire at both telephone contacts and clinic visits. A higher score indicates worse asthma control. Asthma exacerbations were assessed prospectively during the study visits and phone calls, and retrospectively for the first part of pregnancy, with details confirmed by the medical records. Severe exacerbations were defined as requiring medical intervention (hospital admission, emergency department presentation, unscheduled doctor visit or the use of oral corticosteroids (OCS)). Mild exacerbations were defined as those managed by the subject and self-reported as increased symptoms or medication use (inhaled corticosteroids (ICS) or $\beta_{2}$-agonists), or using a written action plan.

During clinical assessments, we measured height, weight, lung function (Spirotrac IV, Vitalograph, Buckingham, UK), fractional exhaled nitric oxide (FENO; NIOX, Aerocline, Solan, Sweden) at a controlled flow rate of $50 \mathrm{ml} / \mathrm{s}$ according to American Thoracic Society guidelines, and exhaled carbon monoxide (ECO; piCO Smokerlyzer Breath CO Monitor, Bedfont, UK). Asthma history, smoking history (past and current, and passive smoke exposure; see online supplement), medication use and self-management skills were assessed by direct questioning, as described previously. ${ }^{27}$ Self-management skills were assessed by a trained asthma educator and included observed inhalation device technique, self-monitoring of symptoms and/or peak flow, written action plan use and understanding, medication adherence and knowledge of asthma and its treatment. Asthma severity was classified as mild, moderate or severe using an integrated severity score from the Australian National Asthma Council guidelines based on symptoms, previous exacerbation frequency and severity, and lung function (see online supplement). ${ }^{28}$ ICS use was expressed as $\mathrm{mg} /$ day of beclomethasone dipropionate (BDP) equivalents, where $1 \mathrm{mg} /$ day BDP was equivalent to $1 \mathrm{mg} /$ day budesonide, and $0.5 \mathrm{mg} /$ day fluticasone dipropionate. Some women used ICS in combination with long-acting $\beta$-agonists (LABAs) either budesonide/ formoterol or fluticasone/salmeterol. Details on marital status and infant outcomes were obtained from medical records.

During phone calls and clinic visits, subjects were asked about symptom frequency (days in past week with night waking, morning symptoms or activity limitation due to asthma), medication use and exacerbations in the past fortnight. Women with current exacerbations were offered an additional clinic visit, where assessments were repeated.
Pregnant women with no diagnosis of asthma $(n=46)$ were prospectively followed from recruitment (mean 14.1 (3.1) weeks) with clinic visits only, at $\sim 18,30$ and 36 weeks gestation, and height, weight, smoking history, spirometry, FENO and ECO were assessed.

Results are presented as mean $\pm \mathrm{SD}$ or median (IOR) as appropriate. Statistical analysis was performed using GraphPad Instat 3.05 (GraphPad Software, San Diego, California, USA) and Stata 7 (StataCorp, College Staion, Texas, USA). Group differences were analysed using analyisis of variance (ANOVA) or Kruskal-Wallis tests for normal or non-normally distributed data, respectively. Post hoc testing was done using the Tukey-Kramer (for ANOVA) or Dunn tests (for Kruskal-Wallis tests). Proportions were compared using the $\chi^{2}$ statistic or the Fisher exact test. Linear and Poisson regression models were used to test the association between smoking and asthma control, and between smoking and asthma exacerbation rates. Additional potential explanatory variables were included in the model and chosen based on demographics (age, marital status), prior known association between the variable and asthma control (asthma severity, ICS use), and to adjust for potential confounding (body mass index (BMI), marital status). ACQ6 was transformed using the square root to provide normality, and the robust cluster option was used to adjust for subjects providing data from multiple exacerbations.

\section{RESULTS \\ Baseline characteristics}

\section{Asthma}

Women with asthma were divided into three groups based on self-reported smoking status (26 never smokers, 27 ex-smokers and 27 current smokers). Current smokers were significantly more likely to be single than never or ex-smokers $(p=0.001)$, had lower body weight than ex-smokers $(p=0.046)$ and had lower FENO than ex-smokers $(p=0.018)$. Lung function was not significantly different between the groups and there was no significant difference in either the first stable ACQ6 or lowest ACQ6 value recorded in each group (data not shown). The asthma pattern was severe in $26 \%$ of current smokers, $29.6 \%$ of ex-smokers and $15.4 \%$ of non-smokers (table 1 ).

Current smokers with asthma reported $4(2.3-7.9)$ pack-years (8.5 years total smoking) and smoked $5-6$ cigarettes per day at each visit, and 5 (4-10) cigarettes/day during the exacerbation visit. Ex-smokers with asthma reported a median (IOR) smoking history of 2.1 (1.5-5.8) pack-years (9 years total smoking), and had quit a median of 1.3 years earlier (range $0-15$ years). There

Table 1 Baseline characteristics of subjects

\begin{tabular}{|c|c|c|c|c|c|c|c|c|}
\hline & \multicolumn{4}{|l|}{ Asthma } & \multicolumn{4}{|l|}{ Control } \\
\hline & $\begin{array}{l}\text { Never smokers } \\
\mathrm{n}=\mathbf{2 6}\end{array}$ & $\begin{array}{l}\text { Ex-smokers } \\
n=27\end{array}$ & $\begin{array}{l}\text { Current smokers } \\
n=27\end{array}$ & p Value & $\begin{array}{l}\text { Never smokers } \\
n=24\end{array}$ & $\begin{array}{l}\text { Ex-smokers } \\
n=15\end{array}$ & $\begin{array}{l}\text { Current smokers } \\
n=7\end{array}$ & p Value \\
\hline Maternal age (years) & $28.7 \pm 4.2$ & $27.6 \pm 4.5$ & $26.4 \pm 5.9$ & NS & $30.0 \pm 3.7^{*}$ & $26.8 \pm 6.0$ & $23.3 \pm 5.3$ & 0.005 \\
\hline Gravidity & $2.5(1-4)$ & $3(1-3)$ & $3(2-4)$ & NS & $1.5(1-3)$ & $2(1-2)$ & $2(1-5)$ & NS \\
\hline Parity & $1(0-2)$ & $0(0-1)$ & $1(0-2)$ & NS & $0(0-1)$ & $0(0-1)$ & $0(0-3)$ & NS \\
\hline Weight (kg) & $75.3 \pm 14.7$ & $80.1 \pm 21.2^{*}$ & $67.3 \pm 12.1$ & 0.046 & $81.8 \pm 17.8$ & $73.9 \pm 18.4$ & $82.1 \pm 19.8$ & NS \\
\hline BMI (antenatal) & $27.8 \pm 5.3$ & $29.2 \pm 6.7$ & $25.2 \pm 4.8^{*}$ & NS & $28.9 \pm 5.0$ & $28.1 \pm 6.4$ & $32.0 \pm 7.3$ & NS \\
\hline$\%$ Single & $1(4 \%)^{*}$ & $4(15 \%)$ & $12(46 \%)$ & 0.001 & $1(4 \%)^{*}$ & $1(8 \%)$ & $4(57 \%)$ & 0.007 \\
\hline$\%$ predicted $\mathrm{FEV}_{1}$ & $96.0 \pm 14.0$ & $92.4 \pm 14.6$ & $92.3 \pm 15.1$ & NS & $99.7 \pm 13.2$ & $94.9 \pm 13.3$ & $102 \pm 8.4$ & NS \\
\hline$\%$ predicted FVC & $101.2 \pm 11.7$ & $99.8 \pm 12.3$ & $99.1 \pm 15.5$ & NS & $106 \pm 13.4$ & $92.9 \pm 27.0$ & $108.9 \pm 10.5$ & NS \\
\hline Lowest FENO (ppb) & $13(10.1-19.6)$ & $17.9(9-30.8)^{*}$ & $8.3(6.6-16.9)$ & 0.018 & $10.2(7.0-13.7)$ & $10.1(8.1-14.9)$ & $7.8(7.0-10.0)$ & NS \\
\hline ECO at visit 1 & $1(1-1)^{*}$ & $1(1-2)^{*}$ & $9.5(4.5-17.5)$ & 0.0001 & $1(1-1)^{*}$ & $1(1-2)^{*}$ & $15(7-22)$ & 0.0001 \\
\hline
\end{tabular}

Values are mean $\pm S D$, median (IOR) or $n$ (\%) of subjects in each group.

*Post hoc test significant $\mathrm{p}<0.017$ vs current smokers.

$\mathrm{BMI}$, body mass index; ECO, exhaled carbon monoxide; FENO, fractional exhaled nitric oxide; FEV $_{1}$, forced expiratory volume in $1 \mathrm{~s}$; FVC, forced vital capacity; NS, not significant. 
were no differences between the smoking groups in reported medication use or adherence during exacerbations (online supplement); however, current smokers had non-significantly poorer asthma medication knowledge.

\section{Control group}

The control group of pregnant women without asthma consisted of 24 never smokers, 15 ex-smokers and 7 current smokers. The current smokers were significantly younger $(p=0.005)$ and were more likely to be single than never and exsmokers $(p=0.007)$. Control smokers had significantly higher ECO than never or ex-smokers $(p=0.0001)$. Current smokers reported 3.8 (2.3-5.4) pack-years (9.5 years total smoking) and smoked 3-8 cigarettes per day at each visit. The ex-smokers in the control group reported a smoking history of 1.9 (1.2-3) pack-years (6years total smoking) and had quit smoking a median of 1 year earlier (range $0-21$ years).

\section{Passive smoking exposure}

Among women with asthma, current smokers were more likely to have a partner who smoked $(\mathrm{p}=0.001)$, allow smoking indoors $\left(p=0.002, \chi^{2}\right.$ test for trend) and have regular visitors who smoked indoors $\left(1-7\right.$ times per week, $p=0.03, \chi^{2}$ test for trend) or outdoors $(1-7$ times per week, $p=0.001)$ than never or ex-smokers (table 2).

In the control group, there was a similar trend for more current smokers to have a partner who smoked ( $p>0.05)$, and current and ex-smokers were more likely to have regular visitors who smoked outside the home (1-7 times per week) compared with never smokers $(p=0.035)$.

\section{Clinical characteristics during asthma exacerbations}

The clinical features during asthma exacerbations are reported in table 3 , and the separate clinical characteristics of mild and severe exacerbations are given in the supplementary material online. Severe exacerbations occurred in $52 \%$ of current smokers, $48 \%$ of ex-smokers and $35 \%$ of never smokers. Cumulative exacerbations during pregnancy were higher in current smokers than never smokers ( $p=0.04$, figure 1$)$. The adjusted severe exacerbation rate was also significantly increased in smokers (current, ex) $(p=0.001)$ and with increased BMI $(p<0.0001)$ (see online supplement).

When subjects' first exacerbation (mild or severe) was analysed (table 3), current smokers had lower FENO during exacerbation (compared with never and ex-smokers, $\mathrm{p}=0.017$ ) and higher ECO during exacerbation (compared with never and ex-smokers, $\mathrm{p}=0.0001$ ). The increase in FENO during subjects' first mild exacerbation was significantly less in current smokers (figure $2 \mathrm{~B}$ ), suggesting these were non-eosinophilic exacerba- tions. For the first severe exacerbation the FENO level (figure 2A) and increase in FENO (figure 2B) were both low in all three groups, indicating a high proportion of non-eosinophilic exacerbations. Current smokers had a median (IOR) increase in ECO during exacerbations of $1(0-4)$ ppm.

Current smokers had a non-significantly higher ACQ6 during exacerbation compared with never smokers (table $3, p=0.056$ ). When the individual ACQ domains were analysed, wheeze was higher in current smokers compared with never smokers, but this did not reach significance. The number of days of morning symptoms reported by current smokers during exacerbation was higher than by never smokers. Linear regression analysis indicated that compared with never smokers, ACQ6 during exacerbation was significantly increased in current smokers when accounting for asthma severity, ICS use and women with multiple exacerbations $(p=0.04)$ (online supplement). Ever smoking compared with never smoking and increased BMI were significantly associated with the number of severe exacerbations experienced by each individual in a Poisson regression model (Supplementary table D).

\section{Neonatal outcomes}

Babies of current smokers were of lower mean birth weight 3207 (574) g than never 3479 (594) g or ex-smokers 3514 (470) g in both the asthma and control groups (asthma, $\mathrm{p}=0.0864$; control, $\mathrm{p}=0.0232$, ANOVA and Tukey-Kramer multiple comparisons test, never vs current smokers).

\section{DISCUSSION}

During pregnancy, asthma exacerbations among current smokers are more frequent and more severe than those of never smokers. Even though the smoking dose was relatively low, the adverse effect of smoking was apparent, with a higher ACO6, increased wheeze and increased frequency of morning asthma symptoms during exacerbations in current smokers. These outcomes did not reach significance possibly due to the small sample size which is a limitation of this study. In addition the rate of smoking among pregnant women with asthma was higher than among controls. We found that $32 \%$ of pregnant women with asthma smoked, while only $15 \%$ of control women smoked. The consequences of this are the known adverse outcomes for the fetus, particularly low birth weight, which we have confirmed, and more troublesome asthma. Together these observations highlight the major importance of smoking by women with asthma as a health problem during pregnancy.

The rate of smoking among pregnant women has been declining in recent decades, and recent data showed that $17 \%$ of Australian women smoked during pregnancy. ${ }^{2}$ Another study also found that smokers were significantly younger and more

Table 2 Passive smoke exposure

\begin{tabular}{|c|c|c|c|c|c|c|c|c|}
\hline & \multicolumn{4}{|l|}{ Asthma } & \multicolumn{4}{|l|}{ Control } \\
\hline & $\begin{array}{l}\text { Never smokers } \\
n=25\end{array}$ & $\begin{array}{l}\text { Ex-smokers } \\
n=27\end{array}$ & $\begin{array}{l}\text { Current smokers } \\
n=22\end{array}$ & p Value & $\begin{array}{l}\text { Never smokers } \\
n=24\end{array}$ & $\begin{array}{l}\text { Ex-smokers } \\
n=27\end{array}$ & $\begin{array}{l}\text { Current smokers } \\
n=21\end{array}$ & p Value \\
\hline Partner smokes & $4(16 \%)^{*}$ & $9(33 \%)^{*}$ & $15(68 \%)$ & 0.001 & $6(25 \%)$ & $5(33 \%)$ & $3(50 \%)$ & NS \\
\hline \multicolumn{9}{|l|}{ Smoking by others in household } \\
\hline Cigarettes/day & $16.5(11.25-20)$ & $12.5(6.25-22.5)$ & $20(12-20)$ & NS & $25(12.5-30)$ & $20(16.3-23.8)$ & $15(15-18)$ & NS \\
\hline No. of others smoking & $\mathrm{n}=4$ & $\mathrm{n}=10$ & $\mathrm{n}=17$ & & $\mathrm{n}=6$ & $\mathrm{n}=6$ & $\mathrm{n}=5$ & \\
\hline Smoking allowed at home & $17(68 \%)$ & $23(85 \%)$ & $20(91 \%)$ & NS & $17(71 \%)$ & $11(73 \%)$ & $6(100 \%)$ & NS \\
\hline Visitors smoking inside home: $>1 /$ week & $0(0 \%)$ & $1(5 \%)$ & $3(17 \%)$ & NS & $0(0 \%)$ & $1(10 \%)$ & $1(25 \%)$ & NS \\
\hline Visitors smoking outside home: $>1 /$ week & $4(18 \%)^{*} \dagger$ & $15(56 \%)$ & $15(71 \%)$ & 0.001 & $3(20 \%)$ & $6(55 \%)$ & $4(80 \%)$ & 0.035 \\
\hline
\end{tabular}

*Post hoc test significant $\mathrm{p}<0.017$ vs current smokers.

tvs ex smokers; NS, not significant.

Values are median (IOR) or $\mathrm{n}(\%)$ of subjects within each group. 
Table 3 Clinical features of asthma exacerbations (mild and severe) during pregnancy

\begin{tabular}{|c|c|c|c|c|}
\hline & Never smokers & Ex-smokers & Current smokers & p Value \\
\hline Events/person & $1.5(1-2)$ & $2(1-3)$ & $2(1-3)$ & NS \\
\hline Lung function at first exacerbation & $\mathrm{n}=13$ & $\mathrm{n}=15$ & $\mathrm{n}=18$ & \\
\hline FENO at exacerbation (ppb) & $23.7(17.9-39.2)^{*}$ & $22.7(15.8-75.7)^{*}$ & $10.7(6.8-18.2)$ & 0.017 \\
\hline ECO at exacerbation (ppm) & $1(1-2)^{*}$ & $1(1-1)^{*}$ & $8(4-19)$ & 0.0001 \\
\hline $\mathrm{FEV}_{1} / \mathrm{FVC}(\%)$ at exacerbation & $80.2(75.0-89.4)$ & $78.0(70.2-83.7)$ & $81.3(74.7-86.1)$ & NS \\
\hline ACQ score at first exacerbation & $\mathrm{n}=21$ & $\mathrm{n}=24$ & $\mathrm{n}=21$ & \\
\hline Overall ACQ6 at exacerbation & $1.17(0.83-2.17)$ & $1.67(1.08-2.75)$ & $2.17(1.67-2.67)$ & NS \\
\hline $\begin{array}{l}\text { Increase in } A C Q \text { (exacerbation) compared with } \\
\text { lowest }(\triangle A C Q)\end{array}$ & $1(1-1)$ & $1(0-2)$ & $2(1-2)$ & NS \\
\hline ACQ6 Domain 1 (Night waking) & $1(0-3)$ & $2(1-3)$ & $2(1-3)$ & NS \\
\hline AC06 Domain 2 (Morning symptoms) & $2(1-2)$ & $2(2-3)$ & $2(2-3)$ & NS \\
\hline Symptoms during exacerbation & $\mathrm{n}=13$ & $\mathrm{n}=15$ & $\mathrm{n}=18$ & \\
\hline Night waking (nights in past week) & $3(0-6)$ & $3(2-7)$ & $3.5(2-5)$ & NS \\
\hline Morning symptoms (mornings in past week) & $3(2-4)$ & $4(0-7)$ & $5.5(3-7)$ & NS \\
\hline Activity limitation (days in past week) & $2(0-3)$ & $0(0-2)$ & $2.5(0-7)$ & NS \\
\hline
\end{tabular}

Values are median (IQR) or $n(\%)$ of subjects in each group.

*Post hoc test significant $\mathrm{p}<0.017$ vs current smokers.

ACQ, asthma control questionnaire; ECO, exhaled carbon monoxide; FENO, fractional exhaled nitric oxide; FEV 1 , forced expiratory volume in 1 s; FVC, forced vital capacity; NS, not significant.

likely to be single than non-smokers, ${ }^{29}$ and both studies used maternal self-report to ascertain smoking history. Neonatal outcomes are improved when women stop smoking early in pregnancy. McCowan et al found that the rates of small for gestational age infants and spontaneous preterm birth were similar in non-smokers and those who quit before 15 weeks gestation, while current smokers had three times the rate of
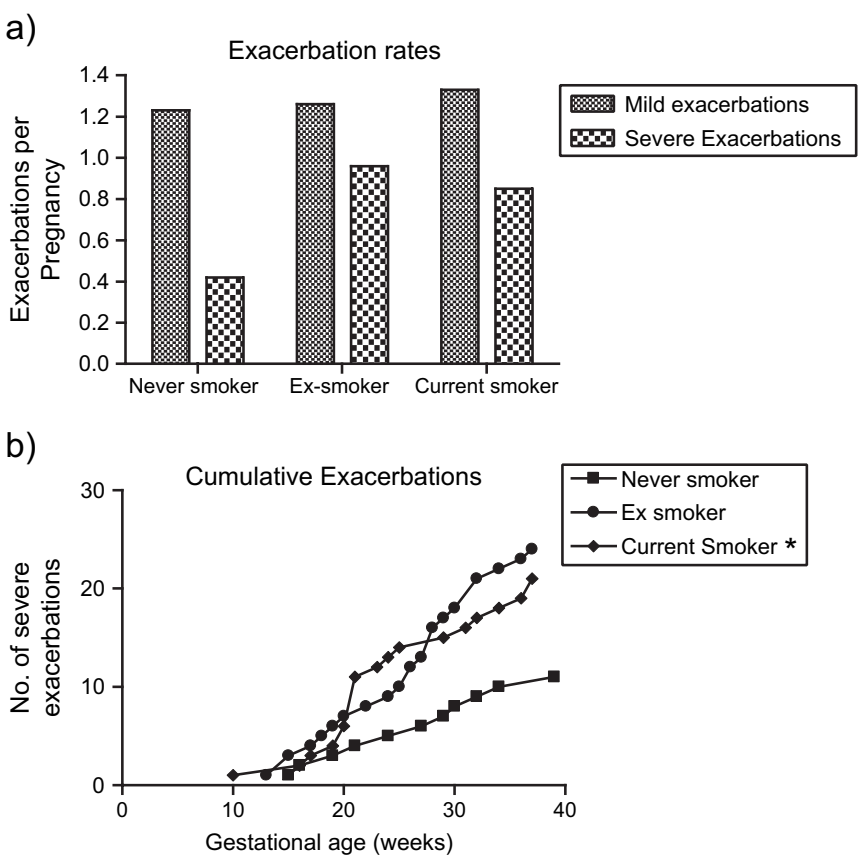

Figure 1 Asthma exacerbations during pregnancy in current smokers, ex-smokers and never smokers. (A) Exacerbation rates of mild and severe exacerbations per pregnancy. (B) Cumulative severe exacerbations during pregnancy by smoking status. ${ }^{*} \mathrm{p}<0.02$ current vs never smokers. preterm birth and almost twice the rate of smaller babies than non-smokers. ${ }^{29}$ There are no data available to assess whether quitting smoking has any health benefits on maternal asthma and this should be an area of further research. In our study, those smokers who had quit smoking (the ex-smoker group) had a similar rate of severe exacerbations to the current smokers, which was almost double that of the never smoker group. This suggests the effect of smoking on asthma during pregnancy can persist even after smoking cessation.

We assessed smoking status by self-report and measurement of ECO. Pregnant women and mothers of young children are a population group who may be reluctant to disclose their smoking status to health professionals, ${ }^{30}$ especially midwives or asthma educators. An ECO concentration of $>9$ ppm has been used to indicate current smoking in pregnancy. ${ }^{31}$ In our study, none of the never smokers or ex-smokers had a value this high at visit 1, or during exacerbation, which provides some validation for our self-reported assessment of smoking status. ECO values are influenced by the time since last cigarette and may not detect light smoking (12 current smokers had ECO values $<9$ ppm at baseline or during exacerbation). Campbell et al assessed selfreported smoking and ECO levels among antenatal clinic attendees in Australia, a group of women similar to our participants. ${ }^{31}$ They found that $23 \%$ of women self-reported smoking, while a further $10 \%$ indicated that they had quit since becoming pregnant. Only $3.3 \%$ of self-reported non-smokers had an ECO reading $\geq 9 \mathrm{ppm}$. Half the smokers reported smoking $<6$ cigarettes per day, ${ }^{31}$ similar to the levels of cigarette use reported in our study. Therefore, our assessment of smoking status has validity. Urinary or serum cotinine levels are more sensitive for detecting active smoking, but were not measured in our study.

Pregnant women whose partner also smokes are twice as likely to continue smoking into late pregnancy than other smokers and recent quitters whose partner does not smoke. ${ }^{32}$ Our data on passive smoking among women with asthma indicated that current smokers were significantly more likely to 
a)

\section{FENO at Exacerbation}

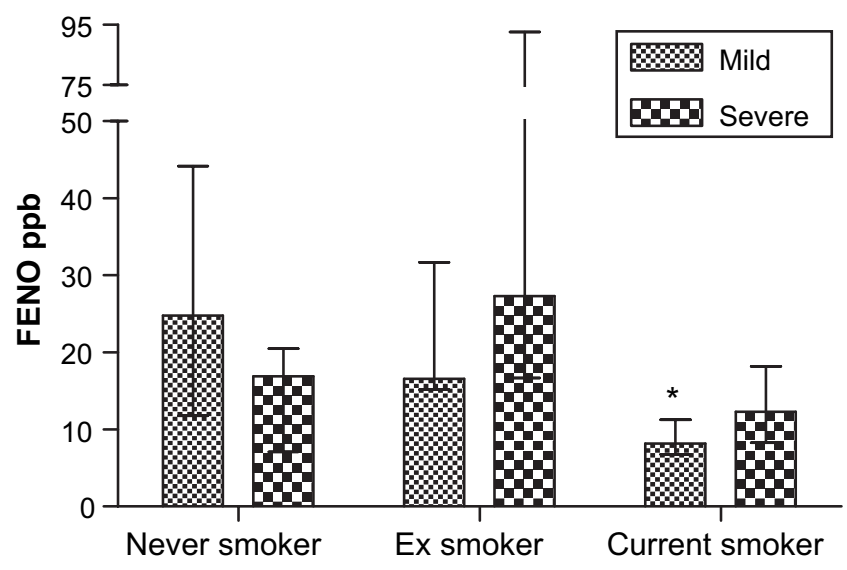

b)

\section{Change in FENO during exacerbation}

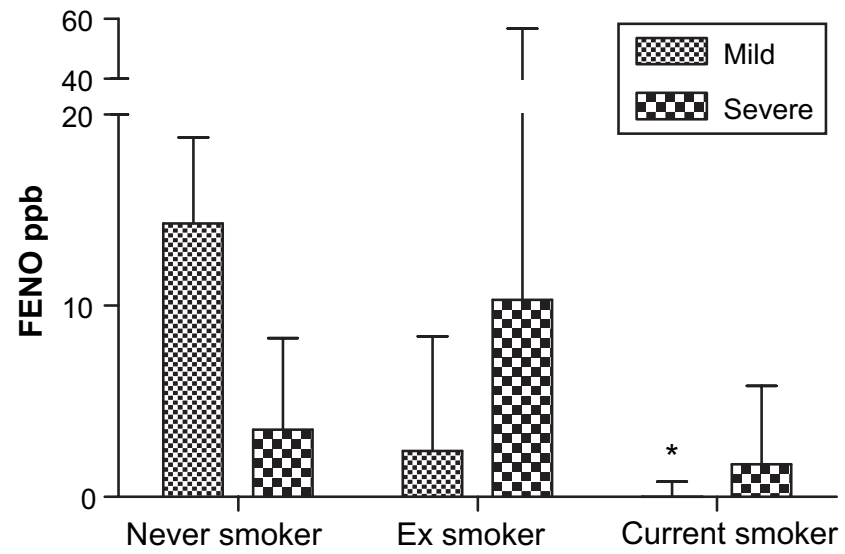

Figure 2 Fractional exhaled nitric oxide (FENO) (A) and change in FENO from the lowest value (B) during the first mild and first severe asthma exacerbations during pregnancy in smokers, ex-smokers and never smokers. ${ }^{*} \mathrm{p}<0.02$ current vs never smoker.

have a partner who smoked, more likely to allow smoking by visitors and to be exposed to denser smoke in public places than never smokers. Exposure to heavy environmental tobacco smoke has been associated with worse asthma symptoms and greater medication requirements in children. ${ }^{33}$ Interventions that target tobacco avoidance in pregnancy need to focus on the household as well as the patient, especially since the adverse effects of smoking seem to occur with low dose tobacco exposure.

Cigarette smoking is associated with persistent changes in asthma, including a more rapid decline of lung function with age, ${ }^{20}$ poorer asthma control, reduced therapeutic response ${ }^{22}$ and greater severity. ${ }^{24}$ In our study, baseline asthma control was not significantly different between never smokers and current smokers. However, during exacerbation, asthma control was worse in smokers than never smokers. This was driven by a higher reported wheeze among current smokers during exacerbation, as well as increased frequency of asthma symptoms on waking in the morning. A study of adult smokers with asthma found that they had a significantly increased ACQ (both total score and individual answers for domains 1-6), but lung function, measured by spirometry (and domain 7 of the ACQ), was not different from the never smokers. ${ }^{21}$ The adults in this study had had a 10 pack-year minimum and smoked an average of 27 years. Both groups of subjects with asthma had a median ACO $>1.5$ (suggesting uncontrolled asthma), despite the fact that they were considered to have been stable on treatment for the past 4 weeks. In another study, the smokers (mean age 46; 25 pack-years) also had significantly higher ACO at baseline (mean ACO7=1.9) compared with non-smokers (mean ACO7 $=1.1){ }^{22}$ Both these groups of adults with asthma were quite different from our cohort of pregnant women, who were younger and had a much lower smoking dose; however, despite this we also found that asthma symptoms were greater in smokers with asthma. It appears that even smoking at a low dose, or for a short duration has the potential to impact adversely on asthma. The observation that forced expiratory volume in $1 \mathrm{~s}\left(\mathrm{FEV}_{1}\right)$ is not (yet) reduced suggests an opportunity for intervention before long-term lung function change occurs.

The reasons for poorer asthma control among smokers, particularly during exacerbation, may be related to medication use, non-adherenc, or a direct effect of smoking on asthma status. Current smokers were less likely to use ICS medications during pregnancy and they also displayed poorer self-management skills. Regression analysis indicated that asthma control during exacerbation was increased among smokers even when considering potential confounders such as ICS use, asthma severity and multiple exacerbations, suggesting a direct effect of smoking on asthma contributing to increased symptom severity. It is known that smokers are relatively insensitive to corticosteroid treatment compared with non-smokers, possibly due to non-eosinophilic inflammation. ${ }^{34}$ The low levels of FENO that we observed during exacerbations are consistent with this. An interaction between a direct smoking effect, or a reduced therapeutic effect of ICS in smokers may cause the increase in symptom severity.

Smokers had an increased ECO during mild exacerbations. This suggests that there may be changes in smoking behaviour associated with exacerbations. Increased cigarette consumption during mild exacerbation may be causal in increasing symptoms or decreasing treatment response which were used to detect exacerbations. The absence of a change in FENO during exacerbations in smokers suggests that they experienced predominantly non-eosinophilic exacerbations, which may be less responsive to corticosteroid treatment.

In conclusion, pregnant women with asthma who smoke have exacerbations which are more severe and more frequent than never smokers. Severe exacerbations during pregnancy are a significant risk factor for low birth weight, ${ }^{19}$ as is smoking itself. ${ }^{1}$ Smoking cessation should be particularly encouraged in pregnant women with asthma, as the effects of asthma on poor perinatal outcomes may be greater among smokers than nonsmokers.

Acknowledgements The authors thank Kelly Steel and Philippa Talbot for conducting the clinical assessments, and Heather Powell for assistance with statistical analysis.

Funding Financial support for this study was provided by the Asthma Foundation of NSW, Hunter Medical Research Institute, Port Waratah Coal Services and University of Newcastle. VEM was the recipient of the Hunter Medical Research Institute/Port Waratah Coal Services Postdoctoral Research Fellowship in Respiratory Medicine and a National Health and Medical Research Council (NHMRC) Australian Research Training Fellowship (Part time, 455626). VLC was the recipient of an NHMRC Senior Research Fellowship (510703). PGG was an NHMRC Practitioner Fellowship recipient.

\section{Competing interests None.}

Ethics approval This study was conducted with the approval of the University of Newcastle and Hunter New England Health Human Research Ethics Committees.

Provenance and peer review Not commissioned; externally peer reviewed. 


\section{REFERENCES}

1. Einarson A, Riordan S. Smoking in pregnancy and lactation: a review of risks and cessation strategies. Eur J Clin Pharmacol 2009;65:325-30.

2. Mohsin M, Bauman AE. Socio-demographic factors associated with smoking and smoking cessation among 426,344 pregnant women in New South Wales, Australia. BMC Public Health 2005;5:138.

3. Dombrowski MP, Bottoms SF, Boike GM, et al. Incidence of preeclampsia among asthmatic patients lower with theophylline. Am J Obstet Gynecol 1986;155:265-7.

4. Alexander S, Dodds L, Armson BA. Perinatal outcomes in women with asthma during pregnancy. Obstet Gynecol 1998;92:435-40.

5. Minerbi-Codish I, Fraser D, Avnun L, et al. Influence of asthma in pregnancy on labor and the newborn. Respiration 1998;65:130-5.

6. Demissie K, Breckenridge MB, Rhoads GG. Infant and maternal outcomes in the pregnancies of asthmatic women. Am J Respir Crit Care Med 1998;158:1091-5.

7. Kurinczuk JJ, Parsons DE, Dawes V, et al. The relationship between asthma and smoking during pregnancy. Women Health 1999;29:31-47.

8. Mihrshahi S, Belousova E, Marks GB, et al. Pregnancy and birth outcomes in families with asthma. J Asthma 2003;40:181-7.

9. Sheiner $\mathbf{E}$, Mazor M, Levy A, et al. Pregnancy outcome of asthmatic patients: a population-based study. J Matern Fetal Med 2005;18:237-40.

10. Bakhireva LN, Jones KL, Schatz M, et al. Asthma medication use in pregnancy and fetal growth. J Allergy Clin Immunol 2005;116:503-9.

11. Kallen B, Otterblad Olausson P. Use of anti-asthmatic drugs during pregnancy. 1. Maternal characteristics, pregnancy and delivery complications. Eur J Clin Pharmacol 2007:63:363-73.

12. Tata LJ, Lewis SA, McKeever TM, et al. A comprehensive analysis of adverse obstetric and pediatric complications in women with asthma. Am J Respir Crit Care Med 2007;175:991-7

13. Bakhireva LN, Jones KL, Schatz M, et al. Safety of leukotriene receptor antagonists in pregnancy. J Allergy Clin Immunol 2007;119:618-25.

14. Enriquez R, Griffen MR, Carroll KN, et al. Effect of maternal asthma and asthma control during pregnancy and perinatal outcomes. J Allergy Clin Immunol 2007;120:625-30.

15. Stenius-Aarniala B, Piirila $P$, Teramo K. Asthma and pregnancy: a prospective study of 198 pregnancies. Thorax 1988;43:12-18.

16. Stenius-Aarniala BS, Hedman J, Teramo KA. Acute asthma during pregnancy. Thorax 1996:51:411-14.

17. Clark JM, Hulme E, Devendrakumar V, et al. Effect of maternal asthma on birthweight and neonatal outcome in a British inner-city population. Paediatr Perinat Epidemiol 2007;21:154-62.

18. Murphy VE, Gibson PG, Smith R, et al. Asthma during pregnancy: mechanisms and treatment implications. Eur Respir J 2005;25:731-50.
19. Murphy VE, Clifton VL, Gibson PG. Asthma exacerbations during pregnancy: incidence and association with adverse pregnancy outcomes. Thorax 2006;61:169-76

20. James AL, Palmer LJ, Kicic E, et al. Decline in lung function in the Busselton Health Study: the effects of asthma and cigarette smoking. Am J Respir Crit Care Med 2005:171:109-14.

21. Chaudhuri R, McSharry C, McCoard A, et al. Role of symptoms and lung function in determining asthma control in smokers with asthma. Allergy 2008;63:132-5.

22. Tomlinson JEM, McMahon AD, Chaudhuri R, et al. Efficacy of low and high dose inhaled corticosteroid in smokers versus non-smokers with mild asthma. Thorax 2005:60:282-7.

23. Siroux V, Pin I, Oryszczyn MP, et al. Relationships of active smoking to asthma and asthma severity in the EGEA study. Eur Respir J 2000;15:470-77.

24. Eisner MD, Iribarren C. The influence of cigarette smoking on adult asthma outcomes. Nicotine Tob Res 2007;9:53-6.

25. Juniper EF, O'Byrne PM, Guyatt GH, et al. Development and validation of a questionnaire to measure asthma control. Eur Respir J 1999;14:902-7.

26. Juniper EF, Svensson K, Mork A, et al. Measurement properties and interpretation of three shortened versions of the asthma control questionnaire. Respir Med 2005:99:553-8.

27. Murphy VE, Gibson PG, Talbot PI, et al. Asthma self-management skills and the use of asthma education during pregnancy. Eur Respir J 2005;26:435-41.

28. National Asthma Council. Asthma Management Handbook. Sydney: 2002.

29. McCowan LME, Dekker GA, Chan E, et al. Spontaneous preterm birth and small for gestational age infants in women who stop smoking early in pregnancy: prospective cohort study. BMJ 2009;338:b1081.

30. Florescu A, Ferrence R, Einarson T, et al. Methods for quantification of exposure to cigarette smoking and environmental tobacco smoke: focus on developmental toxicology. Ther Drug Monit 2009;31:14-30.

31. Campbell E, Sanson-Fisher R, Walsh R. Smoking status in pregnant women: assessment of self-report against carbon monoxide (CO). Addict Behav 2001;26:1-9.

32. Flenady V, MacPhail J, New K, et al. Implementation of a clinical practice guideline for smoking cessation in a public antenatal care setting. Aust NZ J Obstet Gynaecol 2008:48:552-8.

33. Yamasaki A, Hanaki K, Tomita K, et al. Environmental tobacco smoke and its effect on the symptoms and medication in children with asthma. Int $\mathrm{J}$ Environmental Health Research 2009;19:97-108.

34. Chaudhuri R, Livingston E, McMahon AD, et al. Effects of smoking cessation on lung function and airway inflammation in smokers with asthma. Am J Resp Crit Care Med 2006; 174:127-33. 